\title{
COMPARATIVE EFFICACY OF FOUR DIFFERENT SOLID PHASE EXTRACTION CARTRIDGES USED TO DETERMINE TETRACYCLINE IN FOODS OF ANIMAL ORIGIN
}

\author{
M. J. Islam, S. U. Talukder*, A. Y. K. M. M. Rana and A. S. M. Saifullah \\ Institute of Food and Radiation Biology, AERE, Savar \\ Dhaka-1349, Bangladesh
}

\begin{abstract}
Four different types of Solid Phase Extraction (SPE) cartridges namely R-Biopharm (RB), Chromabond (CB), Isolute (IS) and Megabond (MB) were used in this study. Control and spiked samples of beef, chicken and shrimp were also used. Optical Density (OD) values of control and spiked samples were measured with the help of Enzyme Linked Immunosorbent Assay (ELISA) reader. Percent binding values for each SPE cartridges were calculated using OD values of respective control and spiked samples. Based on \% binding values a comparative study of 4 different Solid Phase Extraction (SPE) cartridges was carried out. Analysis of variance indicated no significant differences among the \% binding values considering different samples irrespective of SPE cartridges $(\mathrm{P}=0.821266, \mathrm{~F}=0.201279)$ or different SPE cartridges irrespective of samples $(\mathrm{P}=$ $0.168119, \mathrm{~F}=2.180932$ ). From this study, it can be recommended that any of the four SPE cartridges available in the working area can be used for the analysis of tetracycline from foods of animal origin.
\end{abstract}

Key words: Solid phase extraction, ELISA, optical density, \% binding

\section{INTRODUCTION}

The solid-phase extraction (SPE) is a separation process by which compounds that are dissolved or suspended in a liquid mixture are separated from other compounds in the mixture according to their physical and chemical properties. Analytical laboratories use different solid-phase extraction cartridges to concentrate and purify samples for analysis. Solid-phase extraction cartridge can be used to isolate analytes of interest from a wide variety of matrices including urine, blood, water, beverages, soil, and animal tissue (Guide to Solid Phase Extraction, 1998). Tetracyclines are broad spectrum antibiotics which are commonly used in veterinary medicine to prevent diseases and as an additive in foods of animal origin to promote growth (Carson et al., 1998; Moats, 2000; Schenck and Callery, 1998). These are widely used in dairy cattle, poultry and shrimp (Schenck and Callery, 1998; Tendencia and de la Pena, 2001). The use of antibiotics in animal feed helps increase the animal's ability to absorb feed and reach market weight on time. It may also counteract the effects of crowded living conditions and poor hygiene in intensive animal agriculture system (Environmental Media Services, 2000). Excessive use of these antibiotics may result in residues being present in various agricultural products such as meat, poultry, shrimp, honey, egg etc. Antibiotic residues remains in animal body even after slaughtering if there has been no enough time to their repel (Wilson et al., 2003). Residue of antibiotics in foodstuffs from animal origin could represent a hazard for the consumer of these products. To ensure food safety to consumers, EU, FAO/WHO and FDA have set safe levels for residue tetracyclines in milk $(0.1 \mathrm{mg} / \mathrm{kg})$ (Schenck and Callery, 1998), liver $(0.3 \mathrm{mg} / \mathrm{kg})$, egg $(0.2 \mathrm{mg} / \mathrm{kg})$ and muscle tissue $(0.1 \mathrm{mg} / \mathrm{kg})$ (Cooper et al., 1998). A sensitive and reproducible method named enzyme-linked immunosorbent assay (ELISA) were used in this case. The aim of the study was to compare the efficiency of several SPE cartridges for tetracycline determination from animal tissue by ELISA and to mark out optimal experimental conditions that can later be applied for screening and the quantification of the veterinary drug residue analysis.

\section{MATERIALS AND METHODS \\ Sample Type}

Control samples of muscle tissue of beef, chicken and shrimp were obtained from International Atomic Energy Agency (IAEA), Vienna, Austria. Tetracycline hydrochloride $(21.6 \mathrm{mg}$ ) was taken in a $20 \mathrm{ml}$ volumetric flask and methanol was added up to the mark to prepare stock solution $(1 \mathrm{mg} / \mathrm{ml})$. The stock solution was then diluted

*Corresponding e-mail address: shahabeuddin@yahoo.com 


\section{J. Islam and others}

with distilled water to the desired concentration. Citric acid monohydrate (12.9g), $\mathrm{Na}_{2} \mathrm{HPO}_{4}(10.9 \mathrm{~g})$, EDTA sodium salt $(37.2 \mathrm{~g})$ was taken in a $1000 \mathrm{ml}$ volumetric flask and distilled water was added up to the mark. The $\mathrm{pH}$ was adjusted with saturated citric acid. $\mathrm{NaCl}(9.0 \mathrm{~g}), \mathrm{Na}_{2} \mathrm{HPO}_{4} \times 2 \mathrm{H}_{2} \mathrm{O}(2.85 \mathrm{~g}), \mathrm{NaH}_{2} \mathrm{PO}_{4} \times \mathrm{H}_{2} \mathrm{O}(0.55 \mathrm{~g})$, Tween $20(1 \mathrm{ml})$ was taken in a $1000 \mathrm{ml}$ volumetric flask and distilled water was added up to the mark. The $\mathrm{pH}$ was adjusted with sodium base. Methanol $(100 \%)$ was added with $20 \mathrm{mM}$ oxalic acid $(1.8 \mathrm{~g} / \mathrm{l})$ or oxalic acid dehydrate $(2.522 \mathrm{~g} / \mathrm{l})$.

\section{ELISA test kit and microplate reader}

Ridascreen tetracycline ELISA test kit was purchased from R-Biopharm AG (Darmstadt, Germany), kit lot no. 14420, Art. No. R3503. Test kit contained microplate, tetracycline standard solution, tetracycline-conjugate, antitetracycline-antibody, red chromogen, stop solution, buffer and washing buffer. The microplate reader machine was Thermo Scientific Multiskan FC.

\section{Solid Phase Extraction (SPE) cartridges}

Four different types of SPE cartridges namely R-Biopharm (RB) (100mg), Machery-Nagel Chromabond C18ec (CB) $(3 \mathrm{ml} / 200 \mathrm{mg}$ ), Biotage Isolute C18ec (IS) $(6 \mathrm{ml} / 1 \mathrm{~g})$ and Mega Bond Elute C18 (MB) $(6 \mathrm{ml} / 1 \mathrm{~g})$ were used.

\section{Preparation of control and spiked samples}

Eight control samples each from beef, chicken and shrimp were taken. The samples were homogenized with a rod homogenizer (Ultra turrax) and $5 \mathrm{~g}$ each were taken into 50ml separate centrifuge tubes. Four of each from beef, chicken and shrimp were used as control. Five hundred $\mu 1$ oxytetracycline dihydrate solution $(100 \mu \mathrm{g} / \mathrm{kg})$ was added in rest 4 tubes from beef, chicken and shrimp that were used as spiked samples.

\section{Sample processing}

Twenty five $\mathrm{ml}$ Mcllvaine buffer was added in each tubes, vortexed well and used for refrigerated centrifugation $\left(4000 \mathrm{~g} / 15^{\circ} \mathrm{C} / 10 \mathrm{~min}\right.$.). The supernatant was filtered into $50 \mathrm{ml}$ separate test tube using folded filter paper and the extraction procedure was repeated using same buffer for one more time. Again the supernatant was filtered into the respective tubes.

\section{Solid Phase Extraction (SPE)}

Supernatant of one control and one spiked from beef, chicken and shrimp were used for four different SPE cartridges. They were placed on to suction chamber connected to a pump and the pressure raised to 7 inches $\mathrm{Hg}$. They were conditioned with $2 \mathrm{ml}$ methanol $(100 \%), 2 \mathrm{ml}$ distilled water was added and allowed to pass. Five $\mathrm{ml}$ supernatant was put on the respective cartridges, $3 \mathrm{ml}$ distilled water was added and allowed to pass. Vacuum was reduced to 4 inches $\mathrm{Hg}$ with vessel controller. Two ml elution solution was added, eluents were collected in separate glass tubes and vortexed. Hundred $\mu 1$ eluent was taken into glass tube $(12 \times 75 \mathrm{~mm})$ and $400 \mu 1$ kit buffer was added. Fifty $\mu 1$ of this solution was taken for ELISA. It was done for all control and spiked samples.

\section{ELISA test procedure}

Fifty $\mu \mathrm{l}$ from each tubes were pipetted into corresponding wells. Fifty $\mu \mathrm{l}$ tetracycline antibody solution was added to each well. The plate was covered, mixed gently and incubated at room temperature for 1 hour without shaking. The microplate was washed with washer (Well wash, Thermo Scientific) 3 times with $250 \mu 1$ washing buffer. Hundred $\mu \mathrm{l}$ enzyme conjugate solution was added to each well. The plate was covered, mixed gently and incubated at room temperature for 15 minutes. Again the plate was washed as before. Substrate/chromogen solution of $100 \mu \mathrm{l}$ was added to each well. The plate was covered, mixed gently and incubated at room temperature for 15 minutes. Hundred $\mu \mathrm{l}$ stop solution was added to each well and mixed gently. Finally the measurement was made photometrically at $450 \mathrm{~nm}$.

\section{RESULT AND DISCUSSION}

Table 1 summarizes the OD values of control and spiked sample (beef, chicken and shrimp) of four different catridges. The \% binding values were also calculated to interpret the result in Analysis of Variance which was used for comparing different SPE catridges that will be used for determination of tetracycline. The \% binding 
values showed not much variations for the four different cartridges. It was calculated using the following formula: $\%$ Binding $=(\mathrm{OD}$ of spiked/OD of control $) \times 100$.

Table 1. Optical Density (OD) and \% Binding values with 4 different cartridges for beef, chicken and shrimp (control and spiked)

\begin{tabular}{|c|c|c|c|c|c|c|c|c|c|}
\hline \multirow{3}{*}{$\begin{array}{l}\text { SPE } \\
\text { Cartridges }\end{array}$} & \multicolumn{3}{|c|}{ Beef } & \multicolumn{3}{|c|}{ Chicken } & \multicolumn{3}{|c|}{ Shrimp } \\
\hline & \multicolumn{2}{|c|}{ OD values } & \multirow[t]{2}{*}{$\%$ Binding } & \multicolumn{2}{|c|}{ OD values } & \multirow{2}{*}{$\begin{array}{l}\% \\
\text { Binding }\end{array}$} & \multicolumn{2}{|c|}{ OD values } & \multirow{2}{*}{$\begin{array}{l}\% \\
\text { Binding }\end{array}$} \\
\hline & $* \mathrm{C}$ & $* \mathrm{~S}$ & & $* \mathrm{C}$ & $* \mathrm{~S}$ & & ${ }^{*} \mathrm{C}$ & $* \mathrm{~S}$ & \\
\hline RB & 1.566 & 0.968 & 61.81 & 1.620 & 0.984 & 60.74 & 1.577 & 0.964 & 61.12 \\
\hline CB & 1.572 & 1.028 & 65.39 & 1.441 & 0.943 & 65.44 & 1.499 & 1.090 & 72.71 \\
\hline IS & 1.304 & 0.815 & 62.50 & 1.323 & 0.893 & 67.49 & 1.203 & 0.737 & 61.26 \\
\hline MB & 1.615 & 1.080 & 66.87 & 1.686 & 0.892 & 52.90 & 1.485 & 0.846 & 56.96 \\
\hline
\end{tabular}

Considering different samples irrespective of cartridges, analysis of variance indicated no significant differences $(\mathrm{P}=0.821266, \mathrm{~F}=0.201279)$ among the $\%$ binding values (Table 2). Also considering different cartridges irrespective of samples, analysis of variance indicated no significant differences $(\mathrm{P}=0.168119, \mathrm{~F}=$ 2.180932) among the \% binding values (Table 2).

Table 2. Calculated $\mathrm{P}$ and $\mathrm{F}$ value from $\%$ binding value using ANOVA

\begin{tabular}{cc}
\hline $\begin{array}{c}\text { Considering different samples with SPE cartridges } \\
\text { constant }\end{array}$ & $\begin{array}{c}\text { Considering different SPE cartridges with samples } \\
\text { constant }\end{array}$ \\
\hline $\mathrm{P}=0.821266, \mathrm{~F}=0.201279$ & $\mathrm{P}=0.168119, \mathrm{~F}=2.180932$ \\
\hline
\end{tabular}

However, it could be concluded that whatever SPE cartridges used, there will be no significant differences among the results. It is also recommended that the cartridges (especially among these four types) which are available in the working area would be used for the analysis of tetracycline in foods of animal origin.

\section{REFERENCES}

1. Carson MC, Ngoh MA and Hadley SW (1998). Confirmation of multiple tetracycline residues in milk and oxytetracycline in shrimp by liquid chromatography-particle beam mass spectrometry. Journal of Chromatography $B$ 712: 113 .

2. Cooper AD, Stubbings GWF, Kelly M, Tarbin JA, Farrington WHH and Shearer G (1998). Improved method for the on-line metal chelate affinity chromatography-high-performance liquid chromatographic determination of tetracycline antibiotics in animal products. Journal of Chromatography A 812: 321-6.

3. Environmental Media Services (2000). Agricultural use of antibiotics [Online]. Available at http://www.ems.org/antibiotics/antibiotics_food.html (Verified 26 Sep. 2003). EMS, Washington DC.

4. Moats WA (2000). Determination of Tetracycline Antibiotics in Beef and Pork Tissues Using Ion-Paired Liquid Chromatography. Journal of Agricultural \& Food Chemistry 48: 2244.

5. Schenck FJ and Callery PS (1998). Chromatographic methods of analysis of antibiotics in milk. Journal of Chromatography A. 812: 99.

6. Supelco, Guide to Solid Phase Extraction (SPE) (1998). Sigma Aldrich Company. pp. 9.

7. Tendencia EA and de la Pena LD (2001). Antibiotic resistance of bacteria from shrimp ponds. Aquaculture 195, 193.

8. Wilson J, Otsuki T and Majumdsar B (2003). Balancing food safety and risk: do Drug residue limits affect international trade in beef. The Journal of International Trade \& Economic Development 12: 377 - 402. 